\title{
PENGEMBANGAN APLIKASI "ABANG MADE" ANDROID SEBAGAI MEDIA PENGKAJIAN RESIKO LUKA KAKI DIABETIK
}

\author{
Muh. Syahrul*,Kiki Rizky Aulina*,Megawati Syam*, Saldy Yusuf* \\ *Program Studi Ilmu Keperawatan, Fakultas Keperawatan \\ Universitas Hasanuddin,Makassar \\ E-mail: saldy_yusuf@yahoo.com
}

\begin{abstract}
ABSTRAK
Pendahuluan: Salah satu komplikasi diabetes melitus (DM) adalah luka kaki diabetes (LKD) yang diawali dua faktor risiko, yaitu neuropathy dan angiopathy. Untuk itu Tujuan penelitian ini untuk mengembangkan pengkajian resiko LKD yang fleksibel berbasis aplikasi android. Metode: Penelitian ini merupakan pilot sstudydengan pemilihan sampel dilakukan dengan menggunakan teknik purposive Sampling.Hasil: Penelitian melibatkan 33 partisipan menunjukan bahwa terdapat hasil yang sama antara perbandingan menggunakan Doppler Ankle Brachial Index (ABI), dengan Palpasi Nadi dan Monofilament Test dengan Ipswich Test dalam mendeteksi luka kaki diabetes.Pilot Study ini menunjukkan relatif tidak ada perbedaan antara pencatatan manual dan aplikasi ABANG MADE. Kesimpulan:Pilot studi ini menunjukkan potensi aplikasi ABANG MADE sebagai mediapengkajian resiko LKD.
\end{abstract}

Kata Kunci: diabetes mellitus, luka kaki diabetes, deteksi risiko, aplikasi android

\section{ABSTRACT}

Introduction: One complication of diabetes mellitus (DM) is diabetic foot ulcer (DFU), which begins with two risk factors, namely neuropathy and angiopathy. For this reason, the purpose of this study is to develop a flexible DFU risk assessment based on an android application.Method: this was a quantitative study using a Pilot Study by selecting the sample using the purposive sampling technique. Result: This research was conducted at the Endokrin Polyclinic Wahidin Sudirohusodo hospital for one month with 33 participants. There were similar results between comparison using ABI Doppler and Pedal palpation also comparison between Monofilament test and Ipswich test to detecting diabetic foot ulcers. It showed that the specificity and sensitivity test of diabetic foot checkup using the android application called "ABANG MADE" could be used to detect the risks of diabetic foot ulcers (neuropathy and angiopathy). Conclusion: This study confirmed the feasibility of ABANG MADE as a mobile application in recording diabetic foot assessment.

Keywords: diabetes mellitus, diabetic foot ulcers, risk screening, android application. 
ISSN Cetak 2303-1433

ISSN Online: 2579-7301

\section{PENDAHULUAN}

International Working Group on

Diabetic Foot (IWGDF), menegaskan ada dua jalur patofisiologi Luka Kaki Diabetes(LKD), yaitu kerusakan saraf perifer (neuropati) dan gangguan pembuluh darah perifer (angiopati). Di Indonesia neuropathy merupakan penyebab utama LKD (Soewondo, Ferrario, \& Tahapary, 2013). Sejalan dengan itu, penelitian sebelumnya melaporkan lebih dari seperdua pasien DM telah mengalami risiko LKD baik angiopathy maupun neuropathydengan prevalensi LKD diatas 10\%(Yusuf et al., 2016). Dengan demikian deteksi dini neuropathy dan angiopathy sebagai faktor risiko menjadi hal yang penting dalam manajemen pencegahan LKD.

Saat ini golden standard untuk pemeriksaan neuropathy adalah monofilament test dan dopler Ankle Brachial Index (ABI) untuk pemeriksaan angiopathy(IWGDF, 2013). Masalahnya adalah kedua alat ini relatif mahal, belum tersedia luas dan butuh latihan khusus dalam penggunaannya. Oleh karena itu dibutuhkan alternatif untuk pemeriksaan neuropathy dan angiopathy.Penelitiansebelumnya telah mengevaluasi check up kaki diabetes sebagai alternatif pemeriksaan neuropathy dan angiopathy. Uji validitas antara teknik pemeriksaan monofilament test $(5.07 / 10 \mathrm{~g}$ of Semmes-Weinstein Monofilament test) sebagai golden standard terhadap ipswich test sebagai alternatif memiliki sensitivitas yang cukup tinggi (66.7-100\%) dengan spesifisitas yang memuaskan (80.094.6\%)(Sulasti, Yusuf, Jafar, \& Syam, 2017).Begitu juga dengan teknik palpasi nadi (dorsalis pedis dan posterior tibialis) dalam mendeteksi angiopathy memiliki sensitivitas $(25-100 \%)$ dan spesifisitas (97.5-100\%)(Desri, Yusuf, Jafar, \& Syam, 2017). Penelitian lain mengkonfirmasikan bahwa ipswich testmemiliki sensitivitas $72.7 \%-100 \%$ dan palpasi dorsalis pedis dan posterior tibialis memiliki sensitivitas $100 \%$ (Yuliani, Sulaeha, Sukri, \& Yusuf, 2017). Dengan demikian checkup kaki diabetes (palpasi jari kaki dan nadi kaki) dapat digunakan sebagai alternatif pemeriksaan klinismendeteksi risiko LKD apabila golden standard pemeriksaan tidak tersedia di pelayanan kesehatan.

Masalah penelitian saat ini adalah sistem pencatatan manual membatas komunikasi antar tenaga Kesehatan dari segi jarak dan waktu. Apalagi menghadapi pandemic COVID 19, pasien cenderung menolak untuk berkunjung ke fasilitas pelayanan Kesehatan dan adanya pembatasan kunjungan dan interaksi di pelayanan Kesehatan. Dengan demikin transformasi pengkajian manual menjadi digital termasuk pengkajian resiko LKD menjadi sebuah kebutuhan mendesak. Sejalan dengan itu, tujuan penelitian ini adalah pengembangandan evaluasi aplikasi berbasis android sebagai media pengkajian resiko LKD.

\section{BAHAN DAN METODE}

Penelitian ini merupakan penelitian kuantitatif dengan pendekatan Pilot Study dengan pemilihan sampel dilakukan dengan menggunakan teknik purposivedengan kriteria inklusi usia > 18 tahun, menderita DM, dan dapat membaca serta menulis.. Populasi penelitian ini adalah pasien DM yang beresiko mengalami LKD di Poli Endokrin, RSUP. Dr. Wahidin Sudirohusodo, Makassar. Izin etik diperoleh dari Komite Etik Fakultas Kedokteran Universitas Hasanuddin (UH18050301).

Penelitian ini terdiri atas dua tahap:

1. Pengembangan Aplikasi

Pengembangan aplikasi dengan konsultasi pakar IT berdasarkan prosedur checkup kaki diabetes. Pembuatan aplikasi dibuat dengan software pembuat aplikasi, software yang kami gunakan adalah mit app inventor. Desain dengan menggunakan fitur photoshop dan coreldraw untuk pengeditan dan setelah itu kita mengabungkan kode program untuk mencetak dan me-build kode program yang mudah diterjemahkan sehingga menjadi file yang siap dipakai. Pengem

2. Pelaksanan Penelitian

Uji coba aplikasi terdiri atas dua pemeriksaan, langkah pertama Ipswich 
ISSN Cetak 2303-1433

ISSN Online: 2579-7301

test dalam mendeteksi risiko neuropati sebagai pengganti monofilament test. Kedua adalah palpasi nadi kaki (dorsalis pedis dan posterior tibilias) dalam mendeteksi risiko angiopati sebagai pengganti Doppler Ankle Brachial Index (ABI). Hasil pemeriksaan diinput dalam aplikasi ABANG MADE (Gambar1).

\section{HASIL}

Sebagian besar partisipan berjenis kelamin perempuan sebanyak 22 partisipan (66.7\%), sementara untuk rentang usia, partisipan dengan usia 51-60 tahun dan 6170 tahun memiliki jumlah partisipan terbanyak yaitu 13 partisipan (39.4\%) (Tabel 1). Berdasarkan kategori resiko, mayoritas partisipan $(24,72.2 \%)$ berada dalam resiko 0 (normal) (Tabel 2).Gambaran status angiopati berdasarkan perbandingan pemeriksaan golden standard Doppler ABI didapatkan 17 (68\%), terdengar nadi sekaligus teraba saat palpasi (Tabel 3). Hasil pemeriksaan status neuropati menggunakan Monofilament test, terasa adanya sensasi ditemukan pada 24 (73\%) (Tabel 4).

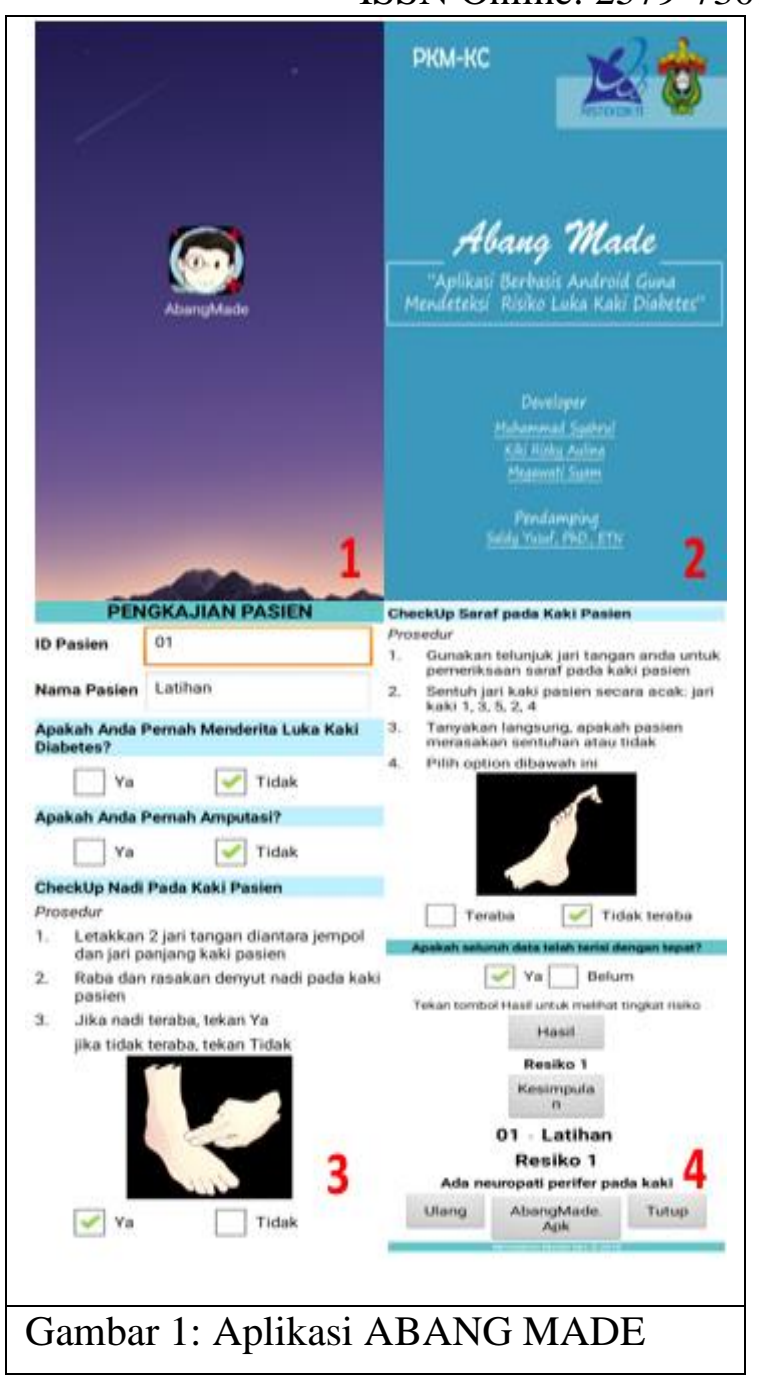

Tabel 1. Data demografi partisipan $(n=33)$

\begin{tabular}{ccc}
$\begin{array}{c}\text { Karakteristik } \\
\text { Demografi }\end{array}$ & $\begin{array}{c}\text { Frekuensi } \\
(\mathbf{n})\end{array}$ & $\begin{array}{c}\text { Persentase } \\
(\boldsymbol{\%})\end{array}$ \\
\hline Jenis Kelamin & & \\
Laki-Laki & 11 & 33.3 \\
Perempuan & 22 & 66.7 \\
Usia & & \\
41-50 Tahun & 4 & 12.1 \\
51-60 Tahun & 13 & 39.4 \\
61-70 Tahun & 13 & 39.4 \\
>70 Tahun & 3 & 9.1 \\
& & \\
\hline
\end{tabular}


Tabel 2 Kategori resiko luka kaki diabetes

\begin{tabular}{lcc}
\hline \multicolumn{1}{c}{ Ketegori } & $\begin{array}{c}\text { Frekuensi } \\
\text { (n) }\end{array}$ & $\begin{array}{c}\text { Persentase } \\
(\%)\end{array}$ \\
\hline Kategori Risiko & & \\
Risiko 0 (Normal) & 24 & 72.2 \\
$\quad$ Risiko 1 (Saraf & 7 & 21.2 \\
tidak teraba dan & & \\
nadi teraba). & & \\
$\quad$ Risiko 2 (Saraf & 2 & 6.6 \\
dan nadi tidak & & \\
teraba) & & \\
Risiko 3A (Pernah & 0 & 0 \\
luka kaki DM). & & \\
$\quad$ Risiko 3B (Pernah & 0 & 0 \\
$\quad$ Amputasi). & & \\
Status Angiopati & & \\
Normal & 19 & 58 \\
$\quad$ Angiopati & 6 & 18 \\
Tidak Terdeteksi & 8 & 24 \\
Status Neuropati \\
berdasarkan
\end{tabular}

Tabel 3 Perbedaan antara pencatatan manual dan Abang Made hasil pemeriksaan Doppler ABI dan Palpasi Nadi

\begin{tabular}{|c|c|c|c|c|c|c|}
\hline \multirow{3}{*}{$\begin{array}{l}\text { Hasil } \\
\text { Doppler } \\
\text { ABI }\end{array}$} & \multicolumn{4}{|c|}{$\begin{array}{c}\text { Palpasi Nadi (Abang } \\
\text { MADE) }\end{array}$} & \multirow{2}{*}{\multicolumn{2}{|c|}{ Total }} \\
\hline & \multicolumn{2}{|c|}{$\begin{array}{l}\text { Tidak } \\
\text { Teraba }\end{array}$} & \multicolumn{2}{|c|}{ Teraba } & & \\
\hline & $\mathrm{n}$ & $\%$ & $\mathrm{n}$ & $\%$ & $\mathrm{n}$ & $\%$ \\
\hline $\begin{array}{r}\text { Tidak } \\
\text { Terdengar }\end{array}$ & 2 & 8 & 4 & 16 & 6 & $24 \%$ \\
\hline Terdengar & 2 & 8 & 17 & 68 & 19 & $76 \%$ \\
\hline Total & 4 & 16 & 21 & 84 & 25 & $100 \%$ \\
\hline
\end{tabular}

Tabel 4. Perbedaan antara pencatatan manual dan Abang Made hasil pemeriksaan Monofilament test dan Ipswich test

\begin{tabular}{rcccccc}
\hline $\begin{array}{c}\text { Monofilament } \\
\text { Test }\end{array}$ & \multicolumn{3}{c}{$\begin{array}{l}\text { Ipswich Test } \\
\text { (ABANG }\end{array}$} & & \\
& \multicolumn{3}{c}{ MADE) } & Total \\
& $\begin{array}{c}\text { Teraba } \\
\text { n }\end{array}$ & $\%$ & Teraba & & \\
& $\mathrm{n}$ & $\%$ & $\mathrm{n}$ & $\%$ \\
\hline Tidak ada & 3 & 9 & 6 & 18 & 9 & $27 \%$ \\
sensasi & & 6 & 22 & 67 & 24 & $73 \%$ \\
Ada sensasi & 2 & 6 & 28 & 85 & 33 & $100 \%$ \\
Total & 5 & 15 & 28 & \\
\hline
\end{tabular}

\section{PEMBAHASAN}

Peneitlian ini bertujuan untuk mengembangakan aplikasi ABANG MADE dan melakukan evaluasi penggunaan di klinis. Di era digitalisasi teknologi informasi, penting untuk melakukan transformasi format pengkajian Asuhan Keperawatan, termasuk pengkajian kaki diabetes. Hal ini semakin mendesak, mengingat dunia menghadapi situasi pandemic Covid 19. Aplikasi ABANG MADE diharapkan dapat menjadi solusi pengkajian kaki diabetes baik di daerah urban maupun rural.

Proses pengembangan ABANG MADE, kami mengupayakan dalam format yang ringan sehingga mudah dalam penggunaannya. ABANG MADE terdiri atas halaman data demografi pasien, cek up Nadi Kaki, cek up Saraf kaki, dan sistem kategori resiko LKD.

Evaluasi penggunaan secara klinis dilakukan di RS, untuk mengetahui feasibilitas ABANG MADE. Sebagai aplikasi pengkajian resiko LKD, evaluasi kami menunjukkan bahwa relative tidak ada perbedaan pencatatan manual dan berbasis aplikasi ABANG MADE antara hasil pemeriksaan Doppler ABI dan palpasi Nadi dorsalis pedis dan posterior tibialis.

Secara umum ada dua penyebab LKD, yaitu kerusakan pembuluh darah perifer (angiopati), dan kerusakan saraf perifer (neuropati). Standar pemeriksaan neurpati adalah monofilament test $(5.07 / 10 \mathrm{~g}$ of Semmes-Weinstein Monofilament test), namun karena alat ini belum tersedia luas, kami sebelumnya telah memperkenalkan pemeriksaan Ipswich test sebagai alternatif. Hasil penelitian kami sebelumnya mengkonfirmasikan ipswich test sebagai alternatif memiliki sensitivitas dan spesifisitas yang memuaskan (80.094.6\%)(Sulasti, Yusuf, Jafar, \& Syam, 2017).Adapun standar pemeriksaan angiopati adalah pemeriksaan Dopler ABI, dangan teknik palpasi nadi (dorsalis pedis dan posterior tibialis) sebagai alternatif. Hasil evaluasi kami juga menunjukkan palpasi nadi dorsalid pedis dan posterior tibilias memiliki sensitifitas dan spesifisitas yang memuaskan (Desri, Yusuf, Jafar, \& 
Syam, 2017)(Yuliani, Sulaeha, Sukri, \& Yusuf, 2017). Dengan demikian ABANG MADE berpotensi digunakan sebagai sistem pencatatan digital dalam pengkajian resiko LKD.

Kami mencatat beberapa keterbatasan dalam penelitian ini. Pertama aplikasi masih berbasis online sehingga penggunaan masih dibatasi oleh ketersedian jaringan internet. Keterbatasan kedua jumlah sample size masih relative terbatas dan belum representatif mewakili berbagai jenis karakter resiko LKD. Kami juga belum melakukan evaluasi subyektif atas penggunaan ABANG MADE dari sudut pandang perawat sebagai calon pengguna. Validitas dan reliabilitas ABANG MADE juga perlu dievaluasi agar memiliki evidence dalam penggunaannya di Klinis.

\section{Implikasi dalam Praktek}

Pilot studi ini menunjukkan aplikasi ABANG MADE dapat menjadi alternatif proses pencatatan hasil pemeriksaan kaki diabetik.

\section{SIMPULAN}

Pilot studi ini menunjukkan potensi aplikasi ABANG MADE sebagai media pencatatan hasil pemeriksaan kaki diabetes.

\section{DAFTAR PUSTAKA}

Desri, N. Y., Yusuf, S., Jafar, N., \& Syam, N. F. (2017). Validity and Reliability Evaluation of Dorsalis Pedis And Posterior Tibial Pulse Palpation For Angiopathy Diabetic Foot Detection: A Multi-Site Cross-Sectional Study. In APETNA Confrence. Bogor, Indonesia.

Indasari, L. N., Rachmawaty, R., \& Yusuf, S. (2017). Reliability of Ipswich Test In Detecting Neuropathy For Patients Diagnosed With Diabetes Mellitus Whose Had And Without Diabetic Foot Ulcer: A Cross Sectional Multisite Study. In APETNA Confrence Bogor, Indonesia.

International, W. Best Practice Guideline: Wound Management in Diabetic Foot Ulcers (2013).

IWGDF. (2012). Pathophysiology of foot ulceration. Retrieved December 22,
2014, from http://iwgdf.org/consensus/pathophysiol ogy-of-foot-ulceration/

Sari, N. M. (2015). Analisis Implementasi Program Pengelolaan Penyakit Kronis (Prolanis) BPJS Kesehatan pada Puskesmas Di Kabupaten Sukoharjo.

Shaw, J. E., Sicree, R. A., \& Zimmet, P. Z. (2010). Global estimates of the prevalence of diabetes for 2010 and 2030. Diabetes Research and Clinical Practice, 87(1), 4-14. doi:10.1016/j.diabres.2009.10.007

Soewondo, P., Ferrario, A., \& Tahapary, D. L. (2013). Challenges in diabetes management in Indonesia: a literature review. Globalization and Health, 9, 63. doi:10.1186/1744-8603-9-63

Sulasti, D., Yusuf, S., Jafar, N., \& Syam, N. F. (2017). Validity and Reliability Evaluation of Monofilament Test And Ipswich Touch Test To Detect The Diabetic Neuropathic Foot of Patients With Diabetes Mellitus: A Multi-Site Cross-Sectional Study. In APETNA Confrence. Bogor, Indonesia.

Yuliani, K., Sulaeha, Sukri, S., \& Yusuf, S. (2017, Juni). Hasanuddin Student

Jurnal. CheckUp Diabetic Foot, Deteksi Dini Risiko Luka Kaki Diabetes

Pada Pasien Diabetes Melitus di Makassar: Uji Sensifitas da Spesifitas, 1 .

Yusuf, S., Kasim, S., Okuwa, M., \& Sugama, J. (2013). Development of an enterostomal therapy nurse outpatient wound clinic in Indonesia: a retrospective descriptive study. Wound Practice and Research, 21(1), 41-47.

Hidayat, A. R., \& Nurhayati, I. (2014). Perawatan kaki pada penderita diabetes melitus di rumah. Jurnal Permata Indonesia, 5(2), 49-54. Retrieved from http://www.permataindonesia.ac.id/wpcontent/uploads/2015/07/201406.pdf

Yusuf, S., Okuwa, M., Irwan, M., Rassa, S., Laitung, B., Thalib, A., ... Sugama, J. (2016). Prevalence and Risk Factor of Diabetic Foot Ulcers in a Regional Hospital, Eastern Indonesia. Open Journal of Nursing, 6(January), 1-10 